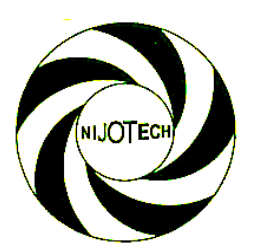

Nigerian Journal of Technology (NIJOTECH)

Vol. 39, No. 2, April 2020, pp. 344 - 350

Copyright@ Faculty of Engineering, University of Nigeria, Nsukka,

Print ISSN: 0331-8443, Electronic ISSN: 2467-8821

www.nijotech.com

http://dx.doi.org/10.4314/njt.v39i2.4

\title{
IMPROVING THE CAPACITY AND OPERATIONAL EFFICIENCY OF AN ON-STREET PARKING SYSTEM USING DATA-BASED PARKING MANAGEMENT STRATEGIES: CASE STUDY OF WATT MARKET IN CALABAR, SOUTH-SOUTH NIGERIA
}

\author{
G. S. Ukam \\ Dept of Civil Engineering, Cross River Univ. Of TeChnology, Calabar, Cross River State, Nigeria \\ E-mail address: georgeukam@gmail.com
}

\begin{abstract}
Solving parking challenges in a manner that is sustainable would require a shift from using up more scarce land resources in providing supply to meet an unending demand for parking. Parking management is the approach of tackling parking challenges that efficiently utilizes scarce resources to meet demand in a sustainable way. This paper studied an on-street parking system in the central business district with the aim of proffering policies and strategies that can help improve the capacity and operational efficiency of the park. Parking inventory and the license plate method were employed in analyzing the parking characteristics of the park. By introducing a parking duration restriction, more capacity could be accommodated on the current available lots. A 90 minute limit would accommodate at least 106 more vehicles and increase the turnover from 13 to 14 vehicles per lot for the duration of survey, thus improving operational capacity and efficiency. The paper shows that parking management strategies that are effective in making the difference should be employed based on adequate field surveys, observations and analysis.
\end{abstract}

Keywords: On street parking, parking capacity, parking management, Parking survey, License plate

\section{INTRODUCTION}

Parking is a critical component of transportation that is most often overlooked or underestimated in the transport planning process [1]. Shoup [2] captures quite clearly the criticality of parking to the transport system efficiency when he posited that "A surprising amount of traffic isn't caused by people who are on their way somewhere. Rather it is caused by people who have already arrived. Our streets are congested in part, by people who have gotten where they want to be but are cruising around looking for a place to park". Thus, if the parking challenge is not sorted out, the street described above would become congested leading to the attendant losses economically, socially and environmentally. Available data supports the position described above. Shoup [2] himself backs up his position by findings from a study that on average, it took eight minutes for a car to find a parking space and within the studied traffic stream, about thirty percent of cars were cruising for parking. Litman [3] submits that a typical automobile is parked 23 hours each day and uses several parking spaces each week, thus underscoring the importance of parking. If transport is the maker and breaker of cities [4], then unplanned parking is the straw that breaks the camel's back. Urbanization is a global phenomenon that is challenging cities and putting a considerable strain on transport demands. With $50 \%$ of the world's population expected to be living in urban areas by 2025 [5], a serious parking challenge arises considering that this increasing population in the urban areas would see a rise in car ownership and other transport means that would need parking. This condition is further exacerbated by the scarce resource of land that is required to provide parking and transport facilities. Tackling the parking problem will require a paradigm shift from the philosophy of providing maximum parking supply at minimal prices, to a more sustainable approach that seeks to provide optimal parking supply and price, efficiently using

* Corresponding author, tel: +234 7036608135 
parking facilities without always seeking to use up more land for building additional facilities [3]. It is widely believed that adopting appropriate parking management strategies are the best way to tackle parking challenges [3], [6],[7]. Parking management involves policies and programs employed towards efficient use of parking resources [3]. Effective parking management can be used as a tool not just to solve parking challenges but to cause behavioural changes in the choice of modes, for regeneration and for revenue generation. Employing adequate policies that tackles parking and indeed transport challenges now and in the future hinges on getting and analyzing appropriate data [8],[9]. This paper is geared towards employing parking management strategies that can improve critical parking characteristics such as; Parking Index, Parking duration and Turnover, of an existing on-street parking system in the central business district (CBD), thus improving its overall capacity and efficiency. It uses data from surveys carried out on the case study park.

\section{LITERATURE REVIEW}

Parking supports three key objectives namely regeneration, restraint and revenue [7]. It can serve as an avenue to support opening areas and zones of low economic activity and stimulate development. In its restraining objective, it can serve to discourage certain behaviors and effect a mode shift as the planners may deem necessary for effective transport coordination. Parking can also serve as a means of revenue generation especially in large cities and urban centers. Parking management therefore involves managing the various interest that these parking objectives can serve within the general framework of land use and transport planning [3]. Parking demand and supply are the key variables for which parking policies and strategies are set out [10]. Policies and strategies are therefore geared towards balancing supply and demand in such a way that the overall transport mobility and objectives are not affected. Pricing has been identified as a key management tool for regulating parking in city centers as well as downtown regions [11]. There seems to be a direct correlation between pricing for parking and change in behavior especially when the parking cost introduced is high. One way that this price sensitivity can be monitored is in the desire to cruise [2]. Shoup [2] studied drivers' responses to prices for curb (on street) parking and off-street parking in several city centers in the united states. It was found that by underpricing curb parking, compared to off street parking, cities create an economic incentive to cruise as the natural response to the marked price differences would be to cruise and wait for a space being vacated by a departing car. Time duration for parking is another useful strategy to manage the supply side of parking. With a limitless parking supply, the few available parking spaces would be utilized by few numbers of vehicle. However, with a time limit imposed, a single parking spot can serve many more vehicle per time compared to a limitless regime. Several cities adopt such a parking duration restrictions and pricing to very useful effects [10],[11].

Parking management policies and strategies are widely accepted to be the best solution to parking challenges [12],[7]. However, the success of any policy or strategy geared towards a better parking system that is sustainable and yield optimal results would depend heavily on accurate and continuous field data [8]. Parking surveys that yield information on the supply of parking (inventory) and the usage (utilization) and other critical data, when properly analyzed within the context of a general transport system and land use policy, will be useful in setting out policy direction and strategies to adopt for efficient parking. Deo Chimba and Onyango [7], studied the license plate survey methodology that is very popular in determining critical parking characteristics that can help in making policy changes. Their major focus was to monitor data collection periods and frequencies to detect which frequency and duration captures desired changes in the parking situation. Power analysis was employed to analyze the rate of turn over and utilization for three critical license plate intervals of 5-20 min, 3040 mins and 40-60 mins for a downtown parking. They found that in other to detect all possible optimal parking characteristics and cost-efficient surveying, the survey interval for license plate method should be less than every 30 mins for down town and beach parks. This recommendation of a $30 \mathrm{~min}$ interval has been reflected in parking studies reported in literature [8] and is adopted for the present work. Maleck [9] carried out a data driven parking management for Clemson university in which a framework for evaluating existing parking management practices that is also capable of improving current practices was developed. This work demonstrated how the collection of detailed parking data can aid parking management. The framework used data from interviews, inventory and utilization to evaluate the need for parking changes. 
New management strategies were employed using the developed framework. Significant improvements were recorded in the utilization and the ability to account for changes in parking.

A typical parking assessment and strategy recommendation for improvement in current trends was carried out by Kolhar [12] using extensive parking study data. Data on parking supply, parking characteristics and willingness to pay was gathered via various surveys. He showed that by employing a variable parking fee and time limit, there will be a considerable reduction in parking demand which was reflected in the level of service of the parking lots. Strategies like prohibiting parking during peak hours for some of the lots studied was proffered based on findings of the unique peak periods of the lots studied.

Studies within literature has showed that unique parking management strategies can be adopted to suit unique parking challenges for a given locality if proper parking studies are carried out. The ability to analyze these field data into reasonable policy output that can tackle parking challenges without necessarily building more and more parking infrastructure would be critical to successful parking planning that is sustainable.

\section{METHODOLOGY}

Parking surveys to ascertain the supply and usage of the on-street parking at Watt Market was carried out. This data was analyzed to provide useful parking characteristics and patterns for the park and was used in making policy recommendations to improve the efficiency and capacity of Watt Market on- street parking. The details of the surveys and approach to each is set out below.

\subsection{The Study Area}

Among the numerous shopping centers in Calabar, Watt Market is one of the oldest and busiest market and it is also located around the central business district (CBD). People of different income groups visit this market everyday as it caters for diverse requirements. Calabar is the capital and busiest city of Cross River State, South South Nigeria, with a population figure of 566,803 people [13]. Calabar is situated at latitude $4.95^{\circ} \mathrm{N}$, longitude $8.32^{\circ} \mathrm{E}$ and 99meters elevation above the sea level. The layout of the study area showing the location of on street parking under study is painted in green (Figure 1).

\subsection{Parking Space Inventory}

A parking space inventory survey provides such information as number of parking lot, lot size, road geometry etc. Two field teams traversed the entire lengths of the designated on-street parking for marking, counting, measuring and recording information on the parking spaces provided.

Parking inventory survey of Watt market car park revealed that there are two designated on street parking spaces (Figure 1) comprising both marked and unmarked parking provisions with a parking charge of 100 naira, which is collected by park operators. It was observed that a lot of the parking slots available were encroached upon by traders to display their wares. This practice reduced available capacity of the park. There was no signage related to parking or markings denoting parking restrictions. The data on the existing parking supply is as follows;

- $\quad$ Number of available parking spaces $=114$ slots

- $\quad$ Number of practical capacity available $=93$ (this was the highest number of spaces occupied while other available spaces were encroached upon by traders to display wares).

- Street width $=10.3$ meters

- Parking court size $=3.0 \times 3.5$ meters

- No traffic management measures in force

\subsection{Parking Beat Survey}

Pilot surveys was first carried out to get the beat teams used to the method and help in planning for the main survey. Parking beat surveys was carried out on two separate days; a week day (Wednesday) and weekend (Saturday).. The choice of days was based on pilot surveys, so that days of maximum utilization can be captured for the analysis. Beat teams patrolled the parking areas at 30 minutes intervals for a duration of 7.5 hours (8:00am $3: 30 \mathrm{pm})$, taking record of vehicle plate numbers using the designated parking spots. The results for each period for each of the survey days was averaged and used as the representative parking usage in the analysis. Table 1 shows the summary of vehicles parked at each survey time for the two survey days and the average. Notice that in the peak periods for the two days, 


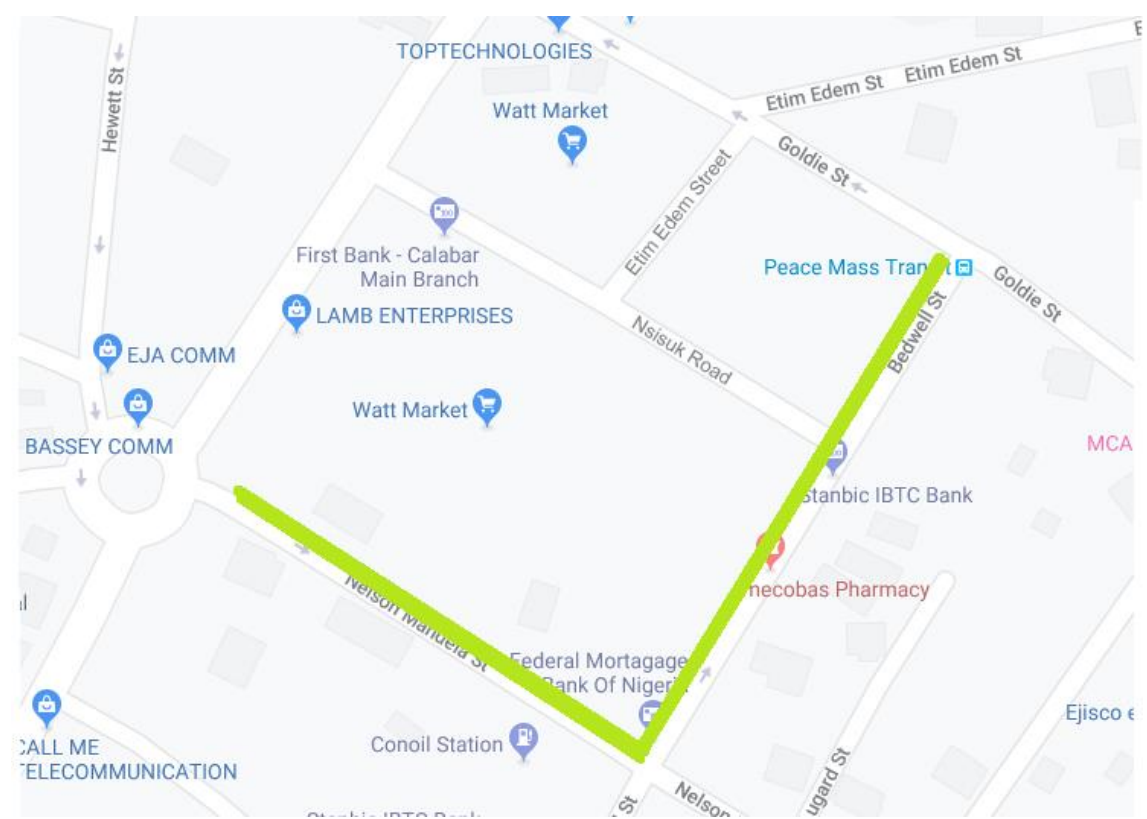

Figure 1: On street parking at Watt Market (Google Map).

Table 1: Summary of results from License plate survey for the two survey days

\begin{tabular}{|l|c|c|c|c|c|c|c|c|c|c|c|c|c|c|c|c|}
\hline TIME & $08: 00$ & $08: 30$ & $09: 00$ & $09: 30$ & $10: 00$ & $10: 30$ & $11: 00$ & $11: 30$ & $12: 00$ & $12: 30$ & $01: 00$ & $01: 30$ & $02: 00$ & $02: 30$ & $03: 00$ & $03: 30$ \\
\hline DAY 1 & 39 & 49 & 51 & 51 & 50 & 59 & 51 & 67 & 81 & 86 & 80 & 64 & 56 & 59 & 56 & 64 \\
\hline DAY 2 & 49 & 75 & 81 & 82 & 91 & 90 & 73 & 88 & 90 & 93 & 93 & 93 & 88 & 84 & 91 & 88 \\
\hline AVRG & $\mathbf{4 4}$ & $\mathbf{6 2}$ & $\mathbf{6 6}$ & $\mathbf{6 7}$ & $\mathbf{7 1}$ & $\mathbf{7 5}$ & $\mathbf{6 2}$ & $\mathbf{7 8}$ & $\mathbf{8 6}$ & $\mathbf{9 0}$ & $\mathbf{8 7}$ & $\mathbf{7 9}$ & $\mathbf{7 2}$ & $\mathbf{7 2}$ & $\mathbf{7 4}$ & $\mathbf{7 6}$ \\
\hline
\end{tabular}

the highest observed utilization was 93 cars. This will be used as the total capacity for analysis as other available spaces were used up by traders for market related activity

\section{RESULT AND ANALYSIS OF PARK CHARACTERISTICS}

The analysis for the parking characteristics of the study area based on observation and data recording from the parking beat survey by patrol is here presented as the average for the two separate survey days.

\subsection{Parking Accumulation}

The parking accumulation shows the total parking at a given instant of time [14]. The Figure 2 shows the accumulation by half hour period.

There is a steady rise in parking demand with time until around 11am where total parking deeps slightly and then continues to rise again. Peak demand occurs around midday.

\subsection{Parking Occupancy}

The percentage of total parking observed to the total capacity for the given time will give the parking occupancy/utilization/index [14]. It gives an indication of how efficiently the park is being utilized.
Figure 3 shows the occupancy of on street parking at Watt Market.

On average, the parking system has an occupancy rate of $78 \%$. The chart shows that occupancy rates at critical peak period from 11:30am - 1:30pm was about $85 \%$.

\subsection{Parking Duration}

This helps to determine the average length of time a vehicle stays in the parking lot. It is a critical parameter when setting time duration restrictions for the car park if such a limit did not exist or the current limit needs adjustment. Figure 4 gives the parking duration in terms of the percentage of vehicles using a parking space.

The analysis shows that $80 \%$ of the vehicles parked spent 90 minutes and less. The real commodity being offered by car parks is vehicle-hours. Matching information about parking duration and utilization of vehicle hours can give a more holistic picture of how time duration and parking relate. Figure 5 shows the parking duration as a percentage of vehicle hours Half hour and one-hour parking durations used up the highest vehicle hours being offered. Vehicles parking for two hours and under accounts for more than $50 \%$ of the available vehicle hours being offered. 


\subsection{Parking Turnover and Turnover Rates}

These parameters measure the efficiency of each parking slot in the park. The turnover is the average number of vehicles using each space throughout the survey (this is the total number of vehicles observed divided by the total number of spaces) while the turnover rate is the turnover divided by the number of hours over which the survey was carried out [15]. Lower value of turn over means the parking bay is utilized by less vehicles and higher turnover means the parking bay is utilized by more vehicles.

In general, higher turnover means better use of parking space over the 7.5 hour period; thus more cars will be serviced by the same parking space.
The analysis shows that on average for the two days of survey 90 parking spaces were used by 1156 cars in a period of 7.5 hours then the rate of parking turnover is about 13 vehicles per parking space for the period of 7.5 hours.

4.5 Improving Operational Efficiency and Optimization of Parking Capacity Through Data Based Parking Duration Restrictions

The existing condition on Watt market off street parking is that a parking charge of 100 naira is taken for parking without any time restriction being enforced.

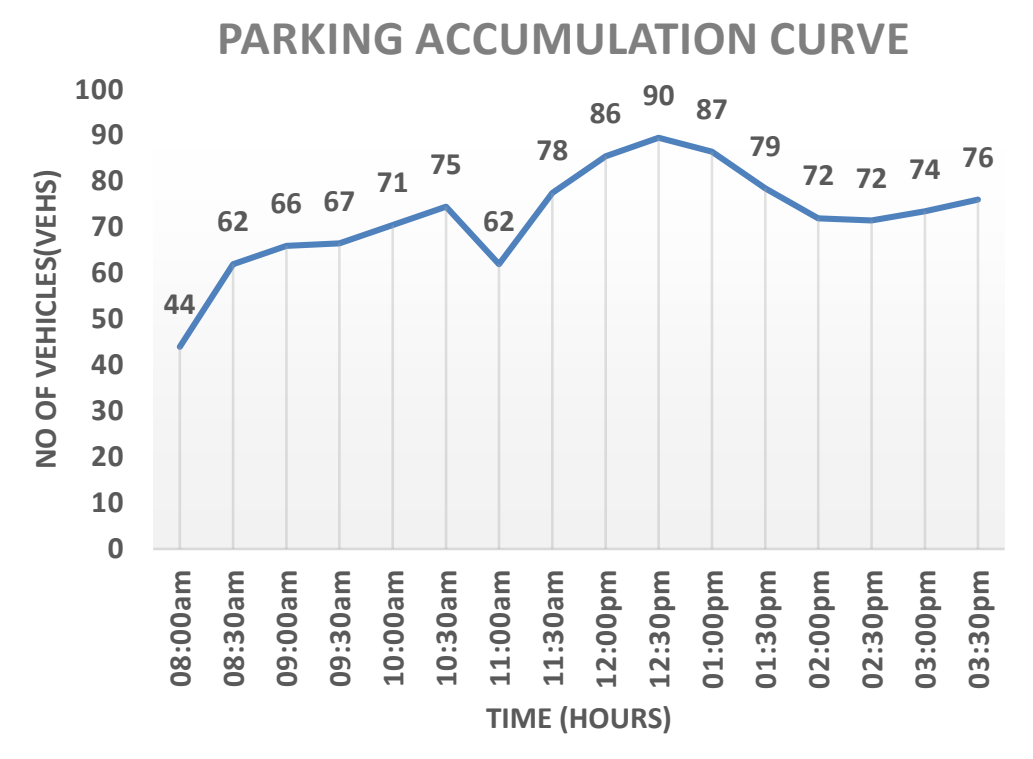

Figure 2: On-Street Parking Accumulation for Watt Market

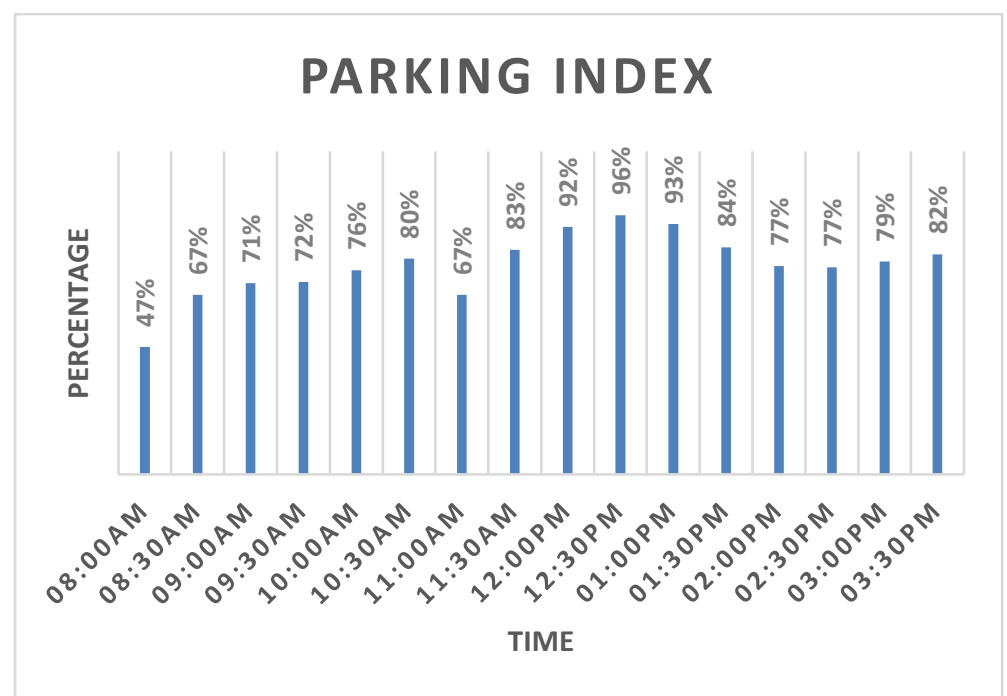

Figure 3: Parking occupancy of On-Street Parking at Watt market 


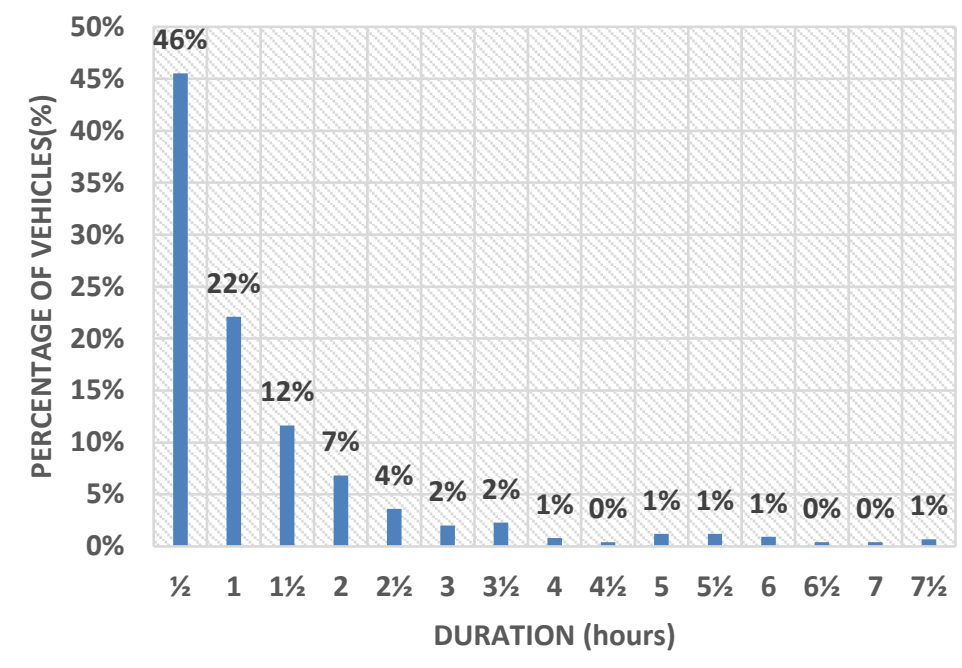

Figure 4: Parking duration for Watt Market park

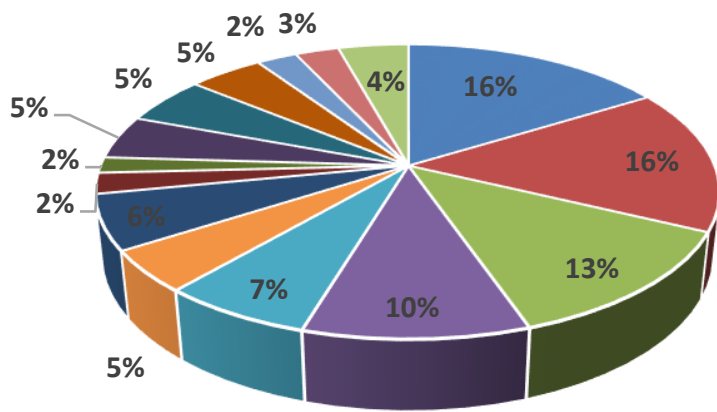

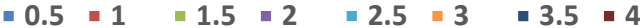

$-4.5=5-5.5=6-6.5=7-7.5$

Figure 5: Parking duration as a percentage of vehicle hours

Such a scenario will stifle turnover, reducing the operational capacity and induce ill effects of parking like cruising, congestion and pollution.

From survey data and analysis carried out above on parking duration, without any real pressure on drivers on their parking duration, about $80 \%$ spent 90 minutes and less parking, representing $50 \%$ of the total vehicle hours. It is believed that the 90 minutes time duration is just enough for the average shopper and from the evidence of parking duration analysis, a larger percentage of vehicles utilized the parking space within this time even when no restrictions were placed on them.

With proper enforcements, best practices still allow for a violation rate in the range of $5-7 \%$ [16]. Adopting the more conservative rate of $7 \%$ violation and the 90minutes parking duration, we can analyze the impacts of enforcing this new time limit policy on the parking characteristics and its improvements of the parking space. About 78 vehicles park for over 90 minutes using a total of 289.5 vehicle hours from the analysis above. At $7 \%$ violation rate, and with adequate enforcement, 73 of the violating vehicles would revert to the new time limit representing about 269 vehicle hours removed from those parking more than the time limit. The vehicles now reverting to the new restrictions will utilize a maximum of about 110 vehicle hours, thus saving 159 vehicle hours that can accommodate about 106 new vehicles at the new stipulated time limit. Thus, within the same parking load, albeit with a new time restriction of 90 minutes and a 7\% violation rate, more than 106 new vehicles can be accommodated, increasing the parking volume to 1262 and a turnover rate of 14 vehicles/lot for the duration of the survey, an increase of 1 vehicle/lot from the current scenario. At the current scenario, from survey data, a total of 1156 vehicle use the park over the 7.5-hour period. At current pricing, revenue accruing to local authorities monthly is over 2.7 million naira. With a new time limit, at least 1262 vehicles would use the park generating over 3 million naira per month and this excluding the extra charge that would come from enforcement of violations of the limit restrictions.

\section{CONCLUSION AND RECOMMENDATIONS}

Parking has always been a critical aspect of transport system planning that can significantly hamper transport planning objectives if not incorporated in the transport system planning framework. Parking management strategies from adequate parking surveys and analysis have proven 
to be effective in tackling parking problems and curb the consequent adverse spillover effects on the general transport systems.

This paper studied an on-street parking system in the central business district with the aim of proffering policies and strategies that help improve the capacity and operational efficiency of the park. Various surveys and analysis of the present operational condition of the park were carried out. Findings from the analysis of field survey data indicates that the operational capacity and efficiency of the park can be improved upon by employing some new policy strategies. Also, significant increases in revenue is accruable if these new strategies are adopted thus providing further incentives to the need to urgently effect a policy change. The following suggestions and recommendations would prove key in improving the on-street parking at Watt Market.

- Introduce a parking duration restriction to the on-street parking. A 90 minutes duration is recommended as it caters to a substantial majority of users. This would increase the turnover, allowing more vehicles to park, thus improving mobility on the street.

- Enforce parking policies. Observations from the field indicate that more parking lots than the total lots used in the study are available, but these extra slots were either used for displaying goods or occupied by abandoned vehicles. Proper enforcement would free up more space and cause violators of duration restrictions to pay the necessary extra charges etc.

- The parking slots should be properly marked out and adequate signage installed at strategic positions in the parking space to inform users on some key aspects of the parking regulations

\section{REFERENCES}

[1] Obot, J. U., Etim, E. E and Atser, J. "Intra-Urban Traffic and Parking Demand in Uyo Urban Area." Global Journal of Social Sciences, 8(2), 61-68, 2009.

[2] Shoup, D. "Cruising for parking." Transport Policy, 13(6), pp.479-486, 2006

[3] Litman, T. "Parking Management: Comprehensive Implementation Guide." Victoria Transport Policy Institute, 2019.

[4] Asiyanbola, R. and Akinpelu, A. "The Challenges of on-street parking in Nigerian cities' transportation routes." International Journal of
Development and Sustainability, 1(2), pp.476489, 2012.

[5] Oyedepo, J. "Performance Analysis of OffStreet Parking around the Central Business District of Akure Southwest Nigeria." Consilience: The Journal of Sustainable Development, 16(1), pp.91-105, 2016.

[6] Subramani, T. "Parking Study on Main Corridors in Major Urban Centre." International Journal of Modern Engineering Research, 2(3), pp.pp742-748, 2012.

[7] Deo Chimba, P. and Onyango, M. "Optimization of Short-Term On-Street Park-Pay License Plate Surveying." Journal of Infrastructure Systems, 18(3), pp.194-201, 2012.

[8] C. A. Arjun and M. S. Nagakumar, "Studies on On-Street Parking Using License Plate Method In Basavangudi Bangalore," Int. J. Emerg. Technol. Eng., no. August, pp. 72-84, 2014.

[9] Maleck, B. "Data driven, performance-based parking management in a university setting". https://tigerprints.clemson.edu/all theses/169 4, Accessed on April 12, 2019.

[10] Young, W. and Miles, C. "A spatial study of parking policy and usage in Melbourne, Australia." Case Studies on Transport Policy, 3(1), pp.23-32, 2015.

[11] Marternini, G., Ferrari, F. and Guga, A. "Application of variable parking pricing techniques to innovate parking strategies. The case study of Brescia." Case Studies on Transport Policy, 5(2), pp.425-437, 2017.

[12] Kolhar, P. "On Street Parking Management Plan and Cost-Benefit Analysis for Dharwad City, Karnataka, India." International Journal of Engineering Research and Applications, 2(3), pp.1654-1665, 2012.

[13] PopulationStat, "Calabar, Nigeria Poulation." [Online]. Available: https://populationstat.com /nigeria/calabar. [Accessed: 27-Dec-2019]

[14] Mathew, T. "Transportation Systems Engineering." Bombay: IIT Bombay, 2014.

[15] O'Flaherty, C. "Transport planning and traffic engineering." London: Arnold, 1997.

[16] C. Worth et al. "2015 Everett Downtown Parking Utilization Study." Portland, Oregun: Rick Williams Consulting, 2016. 